\title{
Diarrhea Prevalence and Associated Factors among Under-Five Children in the Periphery Area of Azezo Sub-city, Gondar, Northwest Ethiopia: A community based cross-sectional study
}

Bikes Destaw Bitew ( $\sim$ bikesdestaw2004@gmail.com )

University of Gondar

\section{Atalay Getachew}

Debre Markos University

Jember Azanaw

University of Gondar

\section{Research Article}

Keywords: Childhood, diarrhea, risk factor, prevalence, Azezo sub-city, Gondar, Ethiopia

Posted Date: February 3rd, 2022

DOI: https://doi.org/10.21203/rs.3.rs-1129227/v2

License: (9) (1) This work is licensed under a Creative Commons Attribution 4.0 International License.

Read Full License 


\section{Abstract}

Background: Although there has been a global decrease in childhood diarrheal disease in parallel with improvements in the standard of living, it remains a significant public health problem that occurs due to poor WASH status and other related factors that cause massive childhood morbidity and mortality particularly in sub-Saharan Africa countries including Ethiopia.

Objective: To assess diarrheal disease prevalence and associated factors among under-five children in the periphery area of Azezo sub-city, Gondar, northwest Ethiopia.

Methods: A community-based cross-sectional study was conducted in April 2019. A simple random sampling technique was applied to recruit the eligible clusters/villages. Structured interview questionnaires were used to collect data. The completed data were entered into Epi Info version 7 and exported to SPSS version 20 for further analysis. A binary logistic regression model was used to process bivariate and multivariable analysis of the data to establish the association between dependent and independent variables. The adjusted odds ratio (AOR) with $95 \% \mathrm{Cl}$ was used for the interpretation of data after controlling the confounders.

Results: The two-week prevalence of U5C diarrheal disease was $24.9 \%$ with $95 \% \mathrm{Cl}$ : (20.4 - 29.7). Age group of 1-12months [AOR: 9.22, 95\%Cl: (2.93-29.04)], age group of 13-24months [AOR: $4.44,95 \% \mathrm{Cl}$ : (1.87-10.56)], low monthly income (AOR: $3.68,95 \% \mathrm{Cl}$ : (1.81-7.51)], small family size [AOR: $0.32,95 \% \mathrm{Cl}$ : (0.16-0.65)], poor hand washing practice [AOR: $8.37,95 \% \mathrm{Cl}$ (3.12-22.52), and immediate feed for cooked foods [AOR: $0.39,95 \% \mathrm{Cl}:(0.19-0.81)]$ were significantly associated factors with childhood diarrhea.

Conclusion: Diarrhea was a common health problem among under-five children in the periphery area of Azezo sub-city. Age of children, family size, monthly income, hand-washing practice, and feeding time for cooked food were identified statistically significant risk factors. Therefore, an appropriate intervention program through health education would be recommended with a focus on identified risk factors to reduce the burden of diarrheal diseases.

\section{Background}

Diarrhea illness remains the significant cause of morbidity and mortality of under-five children globally. However most incidents of childhood diarrhea have occurred in mild and acute cases can lead to severe dehydration, which may consequences in mortality and other health risks as a result of malnutrition (1). The most recurrent clinical form of diarrhea comprises acute watery diarrhea which is characterized by abrupt onset of frequent, watery loose, stools without visible blood, lasting less than two weeks $(2,3)$. Bloody diarrhea; often referred to as dysentery, is marked by visible blood and mucus in the stools (4). Whereas persistent diarrhea is an episode of diarrhea, with or without blood lasts at 14 days and causes substantial weight loss in most patients $(2,4)$. 
Diarrheal illness is a main public health problem around the globe. Internationally, 525, 000 under-5-yearold children die from diarrhea annually, approximately 2195 every single day(5). It accounts for $9 \%$ of child deaths worldwide and making childhood diarrhea the second leading cause of mortality next to pneumonia(6). Although there is a global reduction in the death rates of under-five children, the risk of a child for death earlier the age of under five years remains the highest in sub-Saharan African countries (90 per 1000 live births), which is approximately 7 times higher than that in European Regions (12 per 1000 live births)(7). That implies the burden of diarrheal diseases in developing countries is higher than in more developed countries (8-12).

In Ethiopia, the toll of diarrhea is another killer of under-five children following pneumonia(11). A previous study showed that in Ethiopia the incidence of diarrhea declined from 2000 to 2016, the problem is extremely high for children under five years old by causing loss of fluids with substantial mortality in infancy stages (13). Various studies revealed that diarrheal illness in unindustrialized countries like Ethiopia is due to many reasons such as unsafe water supply, lack of water linked to inadequate hygiene, poor personal and domestic hygiene, poor sanitation, failure to wash hands at the critical time, accessibility of toilet facilities, housing environments, educational status of mothers, and poor feeding practices $(8-12,14,15)$. Still, there is limited evidence in the study area towards diarrheal disease and predictors among under-five children. Therefore, this investigation aimed to evaluate the prevalence of diarrheal disease and associated factors of under-five children in the periphery area of Azezo sub-city, Gondar, northwest Ethiopia.

\section{Methods And Materials}

\section{Study design and period}

A community-based cross-sectional study design was employed to collect data from households having U5C in April 2019.

\section{Study area and population}

The study was conducted at the periphery area located at Azezo sub-city, Gondar, about $727 \mathrm{~km}$ far from Addis Ababa, northwest Ethiopia. According to the 2019 Ethiopian budget year, the total residents of this study area were estimated to be about 68,538 populations. Total population of 68,538 of which urban residents account for about 40,430 while the remaining 28,108 are rural inhabitants. In Azezo periphery area there are more than 513 U5C exists from a total population of 4198 and a total of 901 households with 14 villages.

\section{Sample size determination and sampling technique}

The optimal sample size was determined using a single population proportion formula, $\left[n=Z^{2}{ }_{a / 2}\right.$ * $P(1$ $\left.P)^{\star} D / d^{2}\right]$ based on the following assumptions as $95 \%$ confidence interval $(Z=1.96)$, the proportion of childhood diarrhea $22.1 \%$ a study finding from central Gondar zone(16), and $5 \%$ margin of error (d), and 
design effect ( $D=1.5)$. Then after adding the non -response rate $(5 \%)$, the total sample size was 417 households paired with at least one U5C. Cluster sampling technique was implemented to select ten legible villages with a simple random sampling technique from the total number of fourteen villages present in the study area and then all households with $\mathrm{U} 5 \mathrm{C}$ were recruited in randomly selected villages.

\section{Data collection tools}

Quantitative data were collected through face-to-face interviews with mothers or guardians using a pretested structured questionnaire after being developed by reviewing different related articles $(13,17$, 21-25).

The questionnaires were divided into three sub-sections to address a different part of the questions. Section-l: Socio-demographic and economic factors: age, sex, number of family members, level of education, occupation, religion, housing condition, and household income. Section-II: Water-related factors: distance of water source to the household and waste disposal sites, type of water storage containers, type of water source, eating food prepared, and utensils washed with contaminated water, bathing, and washing in unhygienic water. Section-III: Sanitation factors: availability of human and animal waste and household garbage disposal sites, latrine availability, type of latrine, utilization of latrine, cleanliness of latrine, availability of sewage system, presence of domestic animals and flies inside the house. Section-IV: Behavioral factors: hand-washing practice at critical time, raw and prepared food and drink storage places and handling habits, unclean feeding bottles, washing utensils, cleanliness of domestic places, water drawing practice, cleaning practice of the floor, waste disposal practice, vaccination status and breastfeeding.

\section{Data quality control}

The questionnaire was first prepared in English and then translated to the local language Amharic and back to English for data entry purposes to evaluate the consistency of the questionnaire. Three B.Sc. in Environmental Health professionals were involved in data collection with close supervision after delivering two-day training. Pretest was done from five percent of samples outside of the study area to check the response, language clarity, and appropriateness of the questionnaires before starting the actual data collection. Then the identified ambiguous questions had been corrected before the interview. Every day after data collection each questionnaire was reviewed and checked for its completeness by the supervisors and principal investigators. Double-entry of data and frequency checks were also done during the data entry, processing, and analysis. The test result of Cronbach-alpha was 0.8 , which indicates the acceptable internal consistency of the measurement reliabilities.

\section{Data processing and analysis}

Data were checked for completeness and relevance, coded and entered into Epi Info version 7 computer software, and analyzed using SPSS for Windows version 26. The descriptive statistical (frequency, percentages, mean and standard division ) analysis was used to compute the findings of this study. The 
results were then presented using tables, graphs, and texts. The strength of association of predictors with the outcome variable had been computed using the odds ratio with a $95 \%$ confidence interval. Bivariate analysis was performed to assess the binary relation between the outcome and independent variables. All variables with P-value less than 0.2 were included in the multivariable analysis model and then a P-value of less than 0.05 was considered as statistically significant predictors.

\section{Results}

Socio-demographic and economic characteristics of respondents

Four hundred and seven participants were enrolled in this study with a $100 \%$ response rate. All the respondents were women with a mean $( \pm S D)$ age of $32.5( \pm 5.5)$ years. Most $(96.4 \%)$ of participants were biological mothers. Ninety-two percent (384/417) of the mothers were married and had a median family size was six persons per household. The average family income of participants was 4458 ETB. The majority (62.6\%) of participants could not read and write (Table 1 ).

Diarrheal prevalence among under-five Children

The two-week prevalence of U5C diarrheal disease was $24.9 \%$ with $95 \% \mathrm{Cl}:(20.4,29.7)$ in which watery diarrhea takes a higher proportion, which was $78.8 \%$ of the overall prevalence. The prevalence of underfive diarrhea is higher in children in the age group 13-14 months of age 42(40.4\%) followed by age group $1-12$ months $40(38.5 \%)$. The rest $22(21.1 \%)$ was aged 25 and higher. 
Table 1

Sociodemographic characteristics of the respondents in the periphery area of Azezo sub-city, Gondar, northwest Ethiopia, April 2019 ( $n=417)$.

\begin{tabular}{|c|c|c|c|}
\hline Characteristics & Category & Number & Percent (\%) \\
\hline \multirow[t]{2}{*}{ Relation of the respondent to child } & Mother & 402 & 96.4 \\
\hline & Caretaker & 15 & 3.6 \\
\hline \multirow[t]{3}{*}{ Age of mother/caretaker } & $15-24$ & 21 & 5 \\
\hline & $25-34$ & 221 & 53 \\
\hline & $>35$ & 175 & 42 \\
\hline \multirow[t]{2}{*}{ Marital status of mother/caretaker } & Married & 384 & 92.1 \\
\hline & Unmarried & 33 & 7.9 \\
\hline \multirow[t]{2}{*}{ Education of mother/caretaker } & Educated & 156 & 37.4 \\
\hline & uneducated & 261 & 62.6 \\
\hline \multirow[t]{2}{*}{ Occupation of mother/caretaker } & Housewife & 327 & 78.4 \\
\hline & Employed & 90 & 21.6 \\
\hline \multirow[t]{2}{*}{ Family size } & $\leq 6$ & 266 & 63.8 \\
\hline & $>6$ & 151 & 36.2 \\
\hline \multirow[t]{2}{*}{ Family having livestock } & Yes & 326 & 78.2 \\
\hline & No & 91 & 21.8 \\
\hline \multirow[t]{2}{*}{ The family produce a cash crop } & Yes & 78 & 18.7 \\
\hline & No & 339 & 81.3 \\
\hline \multirow[t]{2}{*}{ Monthly family income (ETB) } & $\leq 4000$ & 236 & 56.6 \\
\hline & $>4000$ & 181 & 43.4 \\
\hline
\end{tabular}

Characteristics of children

Out of 417 study participants, $260(62.4 \%)$ were males. The median age of children was 20 months with IQR: 11-31. The highest number 163 (39.1\%) of children were above twenty months of age. More than half $230(55.1 \%)$ of the children were born in hospitals. About $260(62.4 \%)$ children were partial breastfeeders preceding the survey. The majority $340(87.6 \%)$ of children started their supplementary food at the age of 6 months. The highest numbers 284 (79.4\%) of children were received measles vaccination. Almost half 54(51.9\%) of the diarrheic children were admitted to health institutions (Table 2). 
Table 2

Characteristics of under-five children (U5C) in the periphery area of Azezo sub-city, Gondar, northwest Ethiopia, April 2019 ( $n=417)$.

\begin{tabular}{|c|c|c|c|}
\hline Characteristics & Category & Number & Percent (\%) \\
\hline \multirow[t]{3}{*}{ Age of children (month) } & $\leq 12$ & 122 & 29.3 \\
\hline & $13-24$ & 132 & 31.7 \\
\hline & $>24$ & 163 & 39.1 \\
\hline \multirow[t]{2}{*}{ Sex } & Male & 260 & 62.4 \\
\hline & Female & 157 & 37.6 \\
\hline \multirow[t]{2}{*}{ Childbirth } & Hospital birth & 230 & 55.1 \\
\hline & Home & 187 & 44.9 \\
\hline \multirow[t]{4}{*}{ Birth order } & First & 53 & 12.7 \\
\hline & Second & 83 & 19.9 \\
\hline & Third & 103 & 24.7 \\
\hline & Fourth and above & 178 & 42.7 \\
\hline \multirow[t]{3}{*}{ Current breastfeeding status } & Exclusive & 28 & 6.7 \\
\hline & Partial breastfeeding & 260 & 62.4 \\
\hline & Not breastfeeding & 129 & 30.9 \\
\hline \multirow[t]{2}{*}{ Duration of breastfeeding (month) } & $\leq 20$ & 218 & 52.3 \\
\hline & $>20$ & 199 & 47.7 \\
\hline \multirow[t]{2}{*}{ Started supplementary food (month) $(n=388)$} & $\leq 6$ & 340 & 87.6 \\
\hline & $>6$ & 48 & 12.4 \\
\hline \multirow{2}{*}{$\begin{array}{l}\text { Measles vaccination } \\
(n=356)\end{array}$} & Vaccinated & 284 & 79.7 \\
\hline & Unvaccinated & 72 & 20.3 \\
\hline \multirow[t]{2}{*}{ Two weeks diarrheal disease } & Yes & 104 & 24.9 \\
\hline & No & 313 & 75.1 \\
\hline \multirow[t]{2}{*}{ Type of diarrhea $(n=104)$} & Watery diarrhea & 82 & 78.8 \\
\hline & Blood and mucus & 22 & 21.2 \\
\hline \multirow[t]{2}{*}{ Actions are taken at the household level $(n=104)$} & Diet change & 9 & 8.7 \\
\hline & Health center & 54 & 51.9 \\
\hline
\end{tabular}




\begin{tabular}{|llll|}
\hline Characteristics & Category & Number & Percent (\%) \\
\hline & No treatment & 41 & 39.4 \\
\hline
\end{tabular}

Environmental characteristics

\section{Water-related factors}

Half $221(50.6 \%)$ of the study households with children paired were used drinking water from the unimproved water source. Most of 223 (53.5\%) households were collected water for round within 30 minutes time span. The highest number of households 165 (55.2\%) did not experience household water treatment methods as they are using unprotected drinking water sources. All study households used Jerry can for water storage at home. The majority of households 330(79.1\%) stored water at home for consistent usage. The higher number $178(42.7 \%)$ of households consumed about $60 \mathrm{~L}$ of water per day. However, the larger population segment of the study area experiences a median of 8 days of water shortage per month (Table 3). 
Table 3

Characteristics of drinking water in the periphery area of Azezo sub-city, Gondar, northwest Ethiopia, April $2019(n=417)$.

\begin{tabular}{|c|c|c|c|}
\hline Characteristics & Category & Number & $\begin{array}{l}\text { Percent } \\
(\%)\end{array}$ \\
\hline \multirow[t]{2}{*}{ Water source } & Improved & 206 & 49.4 \\
\hline & Unimproved & 221 & 50.6 \\
\hline \multirow[t]{5}{*}{ Method of household water treatment $n=299$} & Boiling & 5 & 1.7 \\
\hline & Filtering & 4 & 1.3 \\
\hline & $\begin{array}{l}\text { Chlorine/ wuha } \\
\text { agar }\end{array}$ & 29 & 9.7 \\
\hline & Sedimentation & 96 & 32.1 \\
\hline & No treatment & 165 & 55.2 \\
\hline \multirow{2}{*}{$\begin{array}{l}\text { Distance of water source in round trip } \\
\text { (in minutes) }\end{array}$} & $\leq 30$ & 223 & 53.5 \\
\hline & $>30$ & 194 & 46.5 \\
\hline \multirow{3}{*}{$\begin{array}{l}\text { Drinking water storage and collection material (repeated } \\
\text { response) }\end{array}$} & Pot & 6 & 1.4 \\
\hline & bucket & 30 & 7.2 \\
\hline & Jerry can & 417 & 100.0 \\
\hline \multirow[t]{3}{*}{ Daily water consumption per Household( litter) } & $\leq 60$ & 178 & 42.7 \\
\hline & $60-80$ & 93 & 22.3 \\
\hline & $>80$ & 146 & 35.0 \\
\hline \multirow[t]{2}{*}{ The common purpose of Water container } & Yes & 120 & 28.8 \\
\hline & No & 297 & 71.2 \\
\hline \multirow[t]{2}{*}{ Water shortage } & Yes & 330 & 79.1 \\
\hline & No & 87 & 20.9 \\
\hline \multirow[t]{2}{*}{ Frequency of water shortage/month } & $\leq 8$ days & 176 & 42.2 \\
\hline & $>8$ days & 241 & 57.8 \\
\hline \multirow[t]{2}{*}{ Cleaning storage containers before use } & Yes & 389 & 93.3 \\
\hline & No & 28 & 6.7 \\
\hline \multirow[t]{2}{*}{ Water drawing method } & By dipping & 17 & 4.1 \\
\hline & By pouring & 364 & 87.3 \\
\hline
\end{tabular}




\section{Housing status and Sanitation conditions}

Of the total 417 households, about 355 (85.1\%) had mud floors. All households were constructed with corrugated iron sheet roofs. Two-thirds $275(65.9 \%)$ of participants lived in a house having two or more rooms. Nearly three-fourths 281 (74.5\%) of households did not have separate keeping rooms of livestock. Most of the households 277 (66.4\%) did not have latrines. The majority of households $332(79.6 \%)$ disposed of their refuse into the open field (Table 4).

Table 4

Housing and sanitation condition of the participants in the periphery area of Azezo subcity, Gondar, northwest Ethiopia, April 2019 ( $n=417)$.

\begin{tabular}{|llll|}
\hline Characteristics & Category & Number & Percent (\%) \\
\hline Type of floor material & Mud & 355 & 85.1 \\
\cline { 2 - 4 } & Cement & 62 & 14.9 \\
\hline livestock living condition $(n=377)$ & Separated & 96 & 25.5 \\
\cline { 2 - 4 } Number of rooms & Not separated & 281 & 74.5 \\
\hline Latrine availability & $\leq 2$ & 142 & 34.1 \\
\cline { 2 - 4 } & $>2$ & 275 & 65.9 \\
\hline Frequency of latrine cleaning/week $(\mathrm{n}=140)$ & Yes & 140 & 33.6 \\
\cline { 2 - 4 } & No & 277 & 66.4 \\
\hline Feces seen around the compounds & $>1$ & 74 & 52.9 \\
\hline Ways of waste disposal $@$ & Yes & 66 & 47.1 \\
\cline { 2 - 4 } & No & 171 & 41.0 \\
\hline Garbage can & 50 & 12.0 \\
\hline burning & 131 & 31.4 \\
\hline Open field & 332 & 79.6 \\
\hline
\end{tabular}

@One household disposed of the waste by using more than one method.

Behavioral/hygienic practices of the participants 
The majority of $293(70.3 \%)$ household members were poorly practiced hand-washing at the critical time. However, only water is the most accessible hand-wash material for the majority of households accounting for 329 (78.9\%) of the total participants. The larger proportion of the study participants did not have separate food preparing materials for their children. More than three-quarters $(76.7 \%)$ of the study participants fed cooked foods immediately after cooking to their children. Of the one-third (33.6\%) of the participants were had leftover food storing habits. From which about 87 (62.1\%) of participants reheat leftover foods before consumption (Table 5). 
Table 5

Behavioral/hygienic practices of the participants in the periphery area of Azezo sub-city, Gondar, northwest Ethiopia, April $2019(\mathrm{n}=417)$.

\begin{tabular}{|c|c|c|c|}
\hline Characteristics & Category & Number & $\begin{array}{l}\text { Percent } \\
(\%)\end{array}$ \\
\hline \multirow[t]{2}{*}{ Hand-washing practice } & Good & 124 & 29.7 \\
\hline & Poor & 293 & 70.3 \\
\hline \multirow[t]{2}{*}{ Hand washing agents } & Plain Water & 329 & 78.9 \\
\hline & Water with soap & 88 & 21.1 \\
\hline \multirow[t]{2}{*}{ Proper washing of raw food for children $(n=388)$} & Yes & 313 & 80.7 \\
\hline & No & 75 & 19.3 \\
\hline \multirow[t]{2}{*}{ Food purchase from street vendors $(n=388)$} & Yes & 165 & 42.5 \\
\hline & No & 223 & 57.5 \\
\hline \multirow[t]{2}{*}{ Separate materials for child food preparation $(n=388)$} & Yes & 233 & 60.0 \\
\hline & No & 155 & 40.0 \\
\hline \multirow[t]{2}{*}{ Child feeding time after food preparation $(n=356)$} & $\begin{array}{l}\text { Feed } \\
\text { immediately }\end{array}$ & 273 & 76.7 \\
\hline & Feed late & 83 & 23.3 \\
\hline \multirow{2}{*}{$\begin{array}{l}\text { Hand-wash practice of children support with guardians ( } \\
n=388)\end{array}$} & Yes & 356 & 91.7 \\
\hline & No & 32 & 8.3 \\
\hline \multirow[t]{2}{*}{ Left-over food storing habit } & Yes & 140 & 33.6 \\
\hline & No & 277 & 66.4 \\
\hline \multirow[t]{2}{*}{ Reheat left over foods before consumption $(n=140)$} & Yes & 87 & 62.1 \\
\hline & No & 53 & 37.9 \\
\hline \multirow[t]{2}{*}{ Kitchen cleaning habit } & Yes & 343 & 82.3 \\
\hline & No & 30 & 7.1 \\
\hline \multirow[t]{2}{*}{ Child bathing farcicality } & $\begin{array}{l}\text { At home with } \\
\text { bidet }\end{array}$ & 391 & 93.8 \\
\hline & River & 26 & 6.2 \\
\hline
\end{tabular}

Factors associated with the diarrheal disease among under-five children

In the bivariate analysis, level of education, family size, latrine availability, the sanitary condition of the compound, hand hygiene practice at the critical time, shelf time of prepared foods, children's age, 
duration of breastfeeding, measles vaccination, and household monthly income were had p-value $<0.2$ and then they were entered into the multivariate analysis. In the final steps of the multivariable analysis: age of children, family size, hand hygiene practice at critical times, shelf time of prepared foods, and household monthly income were significantly associated with under-five children diarrheal disease. Children between the age group of 13 to 24 months (AOR: 4.44; 95\% Cl: (1.87-10.56]) were 4 times more likely to develop diarrhea relative to more than 24 months age groups. Children aged from 1 to 12 months [AOR: 9.22; 95\% Cl: (2.93-29.04)] were also had higher odds of developing diarrhea when compared with above 24 months age group children. The occurrences of diarrheal disease were significantly associated with a household monthly income in which children of poor families were 3.68 times more likely to develop diarrhea [AOR:3.68; 95\% Cl: (1.81-7.51)] compared to higher-income households. The family size of household members was also associated with childhood diarrheal disease development. Small family size $(\leq 6)$ can reduce childhood diarrhea by $68 \%$ relative to households of higher family size $(>6)$ [AOR: $0.32 ; 95 \% \mathrm{Cl}: 0.16-0.65)]$. The risk of developing diarrhea was 8 times among children with mothers having poor hand washing practice at critical times [AOR: 8.37; 95\% Cl: (3.12-22.52)] in relative to children whose mothers had good hand washing practice at critical times. Moreover, shelf time of prepared food was also one of the significantly associated factors and children who feed cooked foods immediately can reduce the diarrheal disease by $61 \%$ [AOR: $0.39 ; 95 \% \mathrm{Cl}:(0.19-0.81)]$ when compared with children that are feeding cooked foods late (Table 6). 
Table 6

Factor analysis related to diarrhea among under-five children in the periphery area of Azezo sub-city, Gondar, northwest Ethiopia, April 2019 ( $\mathrm{n}=417)$.

\begin{tabular}{|c|c|c|c|c|c|}
\hline \multirow[t]{2}{*}{ Variable } & \multirow[t]{2}{*}{ Category } & \multicolumn{2}{|c|}{ Diarrhea } & \multirow[t]{2}{*}{ COR $(95 \% \mathrm{Cl})$} & \multirow[t]{2}{*}{ AOR (95\%Cl) } \\
\hline & & Yes & No & & \\
\hline \multirow[t]{3}{*}{ Age of child (month) } & $1-12$ & 40 & 82 & $\begin{array}{l}3.12(1.74- \\
5.62)^{\star \star \star}\end{array}$ & $\begin{array}{l}9.22(2.93- \\
29.04) \star \star \star\end{array}$ \\
\hline & $13-24$ & 42 & 90 & $\begin{array}{l}2.99(1.68- \\
5.34)^{\star \star \star}\end{array}$ & $\begin{array}{l}4.44(1.87- \\
10.56)^{\star *}\end{array}$ \\
\hline & $>24$ & 22 & 141 & 1.0 & 1.0 \\
\hline \multirow[t]{2}{*}{$\begin{array}{l}\text { Mother/caretaker level of } \\
\text { education }\end{array}$} & Educated & 48 & 108 & $\begin{array}{l}0.61(0.39- \\
0.96)^{\star}\end{array}$ & $0.73(0.37-1.46)$ \\
\hline & uneducated & 56 & 205 & 1.0 & 1.0 \\
\hline \multirow[t]{2}{*}{ Family size } & $\leq 6$ & 53 & 213 & $\begin{array}{l}0.49(0.31- \\
0.77)^{\star}\end{array}$ & $\underset{* \star}{0.33(0.16,0.65)}$ \\
\hline & $>6$ & 51 & 100 & 1.0 & 1.0 \\
\hline \multirow[t]{2}{*}{$\begin{array}{l}\text { Duration of breast } \\
\text { feeding(month) }\end{array}$} & $\leq 20$ & 65 & 153 & $\begin{array}{l}1.74(1.11- \\
2.75)^{\star}\end{array}$ & $0.97(0.42-2.27)$ \\
\hline & $>20$ & 39 & 160 & 1.0 & 1.0 \\
\hline \multirow[t]{2}{*}{ Measles vaccination } & Unvaccinated & 29 & 43 & 1.0 & 1.0 \\
\hline & Vaccinated & 63 & 221 & $\begin{array}{l}0.42(0.24- \\
0.73)^{\star \star}\end{array}$ & $0.73(0.35-1.54)$ \\
\hline \multirow[t]{2}{*}{ Latrine availability } & Yes & 26 & 114 & 1.0 & 1.0 \\
\hline & No & 78 & 199 & $\begin{array}{l}1.72(1.04- \\
2.83)^{\star}\end{array}$ & $0.59(0.26-1.34)$ \\
\hline \multirow[t]{2}{*}{$\begin{array}{l}\text { Feces seen around the } \\
\text { compound }\end{array}$} & Yes & 75 & 171 & $\begin{array}{l}2.15(1.32- \\
3.48)^{\star \star}\end{array}$ & $1.78(0.82-3.89)$ \\
\hline & No & 29 & 142 & 1.0 & 1.0 \\
\hline \multirow[t]{2}{*}{ Hand washing practice } & Poor & 97 & 196 & $\begin{array}{l}8.27(3.72- \\
18.42)^{* *}\end{array}$ & $\begin{array}{l}8.37(3.12- \\
22.52)^{* \star \star}\end{array}$ \\
\hline & Good & 7 & 117 & 1.0 & 1.0 \\
\hline \multirow[t]{2}{*}{ Child Food consumption time } & $\begin{array}{l}\text { Feed } \\
\text { immediately }\end{array}$ & 62 & 211 & $\begin{array}{l}0.44(0.26- \\
0.75)^{\star \star}\end{array}$ & $0.39(0.19-0.81)$ \\
\hline & Feed late & 33 & 50 & 1.0 & 1.0 \\
\hline
\end{tabular}




\begin{tabular}{|c|c|c|c|c|c|}
\hline \multirow[t]{2}{*}{ Variable } & \multirow[t]{2}{*}{ Category } & \multicolumn{2}{|c|}{ Diarrhea } & \multirow[t]{2}{*}{$\operatorname{COR}(95 \% \mathrm{Cl})$} & \multirow[t]{2}{*}{ AOR $(95 \% \mathrm{Cl})$} \\
\hline & & Yes & No & & \\
\hline \multirow[t]{2}{*}{ Household monthly income } & $\leq 4000$ & 81 & 155 & $\begin{array}{l}3.59(2.15- \\
6.00)^{\star \star \star}\end{array}$ & $\underset{* \star \star}{3.68(1.81-7.51)}$ \\
\hline & $>4000$ & 23 & 158 & 1.0 & 1.0 \\
\hline \multicolumn{6}{|c|}{$*=P$-value $<0.05,{ }^{* *}=p$-value $<0.01, * * *=p$-value $<0.001$} \\
\hline \multicolumn{6}{|c|}{ Hosmer and Lemeshow model fitness test was 0.814 i.e., $P>0.05$} \\
\hline
\end{tabular}

\section{Discussion}

The findings of this study revealed that the two-week prevalence of diarrhea in under-five children was $24.9 \%$ with $95 \% \mathrm{Cl}$ : $(20.4,29.7 \%)$. In the factor analysis of this study, the children's age group, family size, hand wash practice, cooked food retention time, and household income were found statistically significant predictors of childhood diarrheal disease.

In this study, almost a quarter of under-five-children experienced the toll of diarrheal disease (24.9\%). This finding is lower than the findings in rural Burundi (32.6\%)(17), Hodan district Mogadishu-Somalia (47.9\%) (3) and in Arba Minch, Ethiopia (30.5\%)(18). This finding is in line with findings from Eastern Ethiopia (22.5\%)(15), Bahir Dar Zuria district (20\%)(19), rural areas of North Gondar Zone(22.1\%)(16), Senegal $(26 \%)(20)$ and Afar region, (26.1\%)(21). However, This find is higher than the findings in Serobo town Jimma (12\%)(22), Wolaita Sodo (11\%)(23) and the 2016 EDHS national report (12\%)(16), Tanzania $(6.1 \%)(24)$, Northern Nigeria, (12.7\%) (9). These differences might be due to the variation in the sociodemographic characteristics, study setting, environmental factors, study period, behavioral characteristics of the study households. This showed that the occurrence of diarrheal disease was varied among children in different study areas.

In factor analysis outcome, the present study revealed that young children were more exposed to the burden of diarrheal disease. The odds of childhood diarrhea were higher than in children whose age is less than two years when compared with two years and above age groups. This could be due to multiple reasons such as the young children started crawling and walking which increases environmental exposure for infectious agents, children's transition period from exclusive breastfeeding to complementary food supplementation that may be contaminated, and less development of immune systems that may easily be affected by diarrheal diseases. This finding is supported by the findings from the study was done in different parts of Ethiopia such as Kersa district, Afar, Benishangul Gumuz, and Sidama zone $(15,21,25-27)$.

As shown in this study, the burden of diarrheal disease was about 3.5 times higher among children with lower family incomes than their high-income counterparts. This might be related to the inability to access water, sanitation, and hygiene technologies and to cover direct medical costs as well as it might be a 
bottleneck to fulfill the necessary dietary components to their children as a result they might become malnourished and increase the risk of acquiring the diarrheal disease. Our study finding is consistent with the findings in India, Bangladesh, Senegal, Nigeria, Rwanda, and Eretria $(21,28-32)$.

The finding of the current study revealed that lower family size was a protective factor for the burden of childhood diarrhea. This is the fact that high family size might be positively associated with under-five diarrheal disease in which as the number of siblings increases mothers/caretakers are exposed to high burden responsibility in different household activities. As a result, this might be diverted the mother's attention of care to their children and this may create an abandoned opportunity for children to expose unhygienic environments. This study finding is consistent with findings of other similar studies in Kersa district, Sengale, Wolitta Soddo Town, and Eritrea $(15,20,23,28)$.

The current finding was also obtained a statistically significant association of diarrheal disease with poor hand hygiene practices of child guardians at a critical time. The occurrence of childhood diarrhea was increased by eightfold due to poor hand-washing practices after latrine visits, during child meal preparation, and after refuse handling. The possible explanation might be the high microbial load may be exposed to various health threats as contamination of hands by various types of pathogens. This finding was in line with studies in India, Somalia, Ethiopia in which children's whose mothers/caretakers are failed to practice good hand-washing at critical times were at higher risk of diarrhea as compared with children's whose mothers/caretakers who are practicing good hand washing abilities $(3,18,33)$.

The outcome of this study was also indicated that odds of diarrheal disease were strongly associated with the time elapsed for the prepared food given to children. The odds of diarrhea among children who feed cooked foods immediately were lower when compared with children who feed cooked foods that are waiting for an undefined period. This might be due to some strains of pathogenic agents having the capacity to survive and reproduce in prepared foods through time which leads to diarrheal diseases. In addition, the prepared child food may be exposed to recontamination when stored for a long time.

Studies were done in Afar and Dessie Ethiopia showed that long storage of cooked food-related problems was strongly associated with under-five diarrheal disease $(34,35)$.

\section{Limitations}

It is very difficult to establish a causal relationship due to the inherent nature of the cross-sectional study design. Recall and/or social desirability biases may be introduced in interview-based data collection. The self-report of mothers/caretakers may cause under or over-estimation of diarrheal disease outcomes.

\section{Conclusions}

This study demonstrated that childhood diarrheal disease was a common health problem among underfive children in the periphery area of the Azezo sub-city like another part of Ethiopia. Compared with the national and other similar study findings, a higher prevalence of diarrhea was reported in this study area. This study was also identified that children in the young age group, a high family size, low household 
income, poor hand-wash practice, and longtime storage for cooked food were statistically significant potential risk factors of childhood diarrheal diseases. Therefore, an appropriate intervention program through health education would be recommended with a focus on identified risk factors to reduce the burden of diarrheal diseases.

\section{Abbreviations}

AOR: Adjusted odds ratio, COR: Crude odds ratio, EDHS: Ethiopian Demographic and Health Survey, LMICs: low and middle-income countries, MOFD: Ministry of Finance and Education, SDGs: Sustainable Development Goals, UNICEF: United Nations Children's Fund, U5C: Under-Five Children, WASH: Water Sanitation and Hygiene, and WHO: World Health Organization

\section{Declarations}

Ethics approval and consent to participate

Ethical clearance and approval were obtained from the research and ethical review committee of the University of Gondar, Institute of public health, department of Environmental and Occupational Health and Safety. Supportive letters were obtained from Azezo sub-city health office to get permission and acceptance. The written informed consent was obtained from all subjects and/or their legal guardian(s). The participants that are mothers/caretakers with child paired had been informed about the aim of the study and the right to withdraw at any time if they were felt discomfort. The participant's privacy and confidentiality were strongly maintained using codes rather than personal identifiers. A statement to confirm that all methods were carried out following relevant guidelines and regulations of the crosssectional study.

\section{Consent for publication}

Not applicable in consent for publication due to participants' images or identity revealing data is not used.

\section{Availability of data}

All data generated or analyzed during this study are included in this to be published article [and its supplementary information files].

\section{Conflicts of Interest}

The authors declared that they have no conflicts of interest in financial and non-financial perspectives.

\section{Funding}


This study had no special fund. However, the University of Gondar had covered questionnaire duplication and data collection fees.

\section{Authors' Contributions}

All stated authors BDB, AG, and JA were actively involved in the study from the inception to design, acquisition of data, analysis, and interpretation, and drafting of the manuscript. All authors have read and agreed to its content and that the manuscript conforms to the journal's policies.

\section{Acknowledgments}

We would like to express our sincere acknowledgments to the University of Gondar, Department of Environmental and Occupational Health and Safety, data collectors, supervisors, and study participants

\section{Author Details}

${ }^{1}$ Department of Environmental and Occupational Health and Safety, Institute of Public Health, College of Medicine and Health Sciences, University of Gondar, Gondar Ethiopia. ${ }^{2}$ Department of Environmental Health, Debre Markos University, Debre Markos, Ethiopia

\section{References}

1. Organization WH. Ending preventable child deaths from pneumonia and diarrhoea by 2025: the integrated Global Action Plan for Pneumonia and Diarrhoea (GAPPD). 2013.

2. Kimani HM. Assessement of diarrhoeal disease attributable to water, sanitation and hygiene among under five in Kasarani, Nairobi County. Department of Community Health, School of Public Health, Kenyatta University. 2013.

3. Warsame HA. Morbidity of diarrheal disease among children aged under five years living in internally displaced population camps of Hodan district, Mogadhishu-Somalia 2016.

4. Unicef. Diarrhoea: Why children are still dying and what can be done. http://www UNICEF org/media/files/Final_Diarrhoea_Report_October_2009_final pdf. 2010.

5. UNICEF W. Diarrhoea remains a leading killer of young children, despite the availability of a simple treatment solution. UNICEF data: monitoring the situation of children and women, Updated: Jun. 2016.

6. Kyu HH, Pinho C, Wagner JA, Brown JC, Bertozzi-Villa A, Charlson FJ, et al. Global and national burden of diseases and injuries among children and adolescents between 1990 and 2013: findings from the global burden of disease 2013 study. JAMA pediatrics. 2016;170(3):267-87.

7. Kasye D, Garoma N, Kassa M. Assessments of the prevalence of diarrhea disease under-five children Serbo town, Jimma Zone Southwest Ethiopia. Clin Mother Child Health. 2018;15:281.

8. Azage M, Kumie A, Worku A, Bagtzoglou AC. Childhood diarrhea in high and low hotspot districts of Amhara Region, northwest Ethiopia: a multilevel modeling. Journal of Health, Population and 
Nutrition. 2016;35(1):13.

9. Hussein H. Prevalence of Diarrhea and Associated Risk Factors in Children Under Five Years of Age in Northern Nigeria: A Secondary Data Analysis of Nigeria Demographic and Health Survey 2013. 2017.

10. Bui HV. The most common causes of and risk factors for diarrhea among children less than five years of age admitted to Dong Anh Hospital, Hanoi, Northern Vietnam 2006.

11. Alebel A, Tesema C, Temesgen B, Gebrie A, Petrucka P, Kibret GD. Prevalence and determinants of diarrhea among under-five children in Ethiopia: A systematic review and meta-analysis. PLoS ONE. 2018;13(6):e0199684.

12. Asnakew DT, Teklu MG, Woreta SA. Prevalence of diarrhea among under-five children in health extension model households in Bahir Dar Zuria district, north-western Ethiopia. Health. 2017;4:1-9.

13. Woldeamanuel BT. Trends and Factors Associated with Healthcare Utilization for Childhood Diarrhea and Fever in Ethiopia: Further Analysis of the Demographic and Health Surveys from 2000 to 2016. Journal of Environmental and Public Health. 2020;2020.

14. Beyene SG, Melku AT. Prevalence of Diarrhea and Associated Factors Among Under Five Years Children in Harena Buluk Woreda Oromia Region, South East Ethiopia, 2018. Journal of Public Health International. 2018;1(2):9.

15. Mengistie B, Berhane $Y$, Worku A. Prevalence of diarrhea and associated risk factors among children under-five years of age in Eastern Ethiopia: A cross-sectional study. Open Journal of Preventive Medicine. 2013;3(07):446.

16. Getachew A, Guadu T, Tadie A, Gizaw Z, Gebrehiwot M, Cherkos DH, et al. Diarrhea Prevalence and Sociodemographic Factors among Under-Five Children in Rural Areas of North Gondar Zone, Northwest Ethiopia. International Journal of pediatrics. 2018;2018.

17. Diouf K, Tabatabai P, Rudolph J, Marx M. Diarrhoea prevalence in children under five years of age in rural Burundi: an assessment of social and behavioural factors at the household level. Global health action. 2014;7(1):24895.

18. Mohammed S, Tamiru D. The burden of diarrheal diseases among children under five years of age in Arba Minch District, southern Ethiopia, and associated risk factors: a cross-sectional study. International scholarly research notices. 2014;2014.

19. Asnakew DT, Teklu MG, Woreta SA. Prevalence of diarrhea among under-five children in health extension model households in Bahir Dar Zuria district, north-western Ethiopia. Edorium Journal of Public Health. 2017;4:1-9.

20. Thiam S, Diène AN, Fuhrimann S, Winkler MS, Sy I, Ndione JA, et al. Prevalence of diarrhoea and risk factors among children under five years old in Mbour, Senegal: a cross-sectional study. Infectious diseases of poverty. 2017;6(1):1-12.

21. Woldu W, Bitew BD, Gizaw Z. Socioeconomic factors associated with diarrheal diseases among under-five children of the nomadic population in northeast Ethiopia. Tropical medicine and health. 2016;44(1):1-8. 
22. Kasye DG, Garoma NH, Kassa MA. Assessment of the prevalence of diarrheal disease under-five children Serbo Town, Jimma Zone South West Ethiopia. Clin Mother Child Health. 2018;15(281):2.

23. Alambo KA. The prevalence of diarrheal disease in under five children and associated risk factors in Wolitta Soddo Town, Southern, Ethiopia. ABC Research Alert. 2015;3(2).

24. Mashoto KO, Malebo HM, Msisiri E, Peter E. Prevalence, one-week incidence and knowledge on causes of diarrhea: a household survey of under-fives and adults in Mkuranga district, Tanzania. BMC public health. 2014;14(1):1-8.

25. Beyene H, Deressa W, Kumie A, Grace D. Determinants of diarrhoeal morbidity: The case of children under five years of age among agricultural and agro-pastoralist community of southern Ethiopia. Ethiopian Journal of Health Development. 2018;32(1).

26. Stanly AM, Sathiyasekaran B, Palani G. A population based study of acute diarrhoea among children under 5 years in a rural community in South India. Sri Ramachandra Journal of Medicine. 2009;1(1):17.

27. Mihrete TS, Alemie GA, Teferra AS. Determinants of childhood diarrhea among underfive children in Benishangul Gumuz regional state, north West Ethiopia. BMC pediatrics. 2014;14(1):1-9.

28. Woldemicael G. Diarrhoeal Morbidity among Young Children in Eritrea: Environmental and SocioeconomicDeterminants. Journal of Health, Population and Nutrition,. 2001;19.

29. Baker KK, Farzana FD, Ferdous F, Ahmed S, Das SK, Faruque A, et al. Association between moderateto-severe diarrhea in young children in the global enteric multicenter study (GEMS) and types of handwashing materials used by caretakers in Mirzapur, Bangladesh. The American journal of tropical medicine and hygiene. 2014;91(1):181-9.

30. He Z, Bishwajit G, Zou D, Yaya S, Cheng Z, Zhou Y. Burden of common childhood diseases in relation to improved water, sanitation, and hygiene (WASH) among Nigerian children. International journal of environmental research and public health. 2018;15(6):1241.

31. Ferdous F, Das SK, Ahmed S, Farzana FD, Latham JR, Chisti MJ, et al. Severity of diarrhea and malnutrition among under five-year-old children in rural Bangladesh. The American journal of tropical medicine and hygiene. 2013;89(2):223.

32. Ngabo F, Mvundura M, Gazley L, Gatera M, Rugambwa C, Kayonga E, et al. The economic burden attributable to a child's inpatient admission for diarrheal disease in Rwanda. PLoS One. 2016;11(2):e0149805.

33. Regassa W, Lemma S. Assessment of diarrheal disease prevalence and associated risk factors in children of 6-59 months old at Adama District rural Kebeles, eastern Ethiopia, January/2015. Ethiopian journal of health sciences. 2016;26(6):581-8.

34. Gizaw Z, Woldu W, Bitew BD. Child feeding practices and diarrheal disease among children less than two years of age of the nomadic people in Hadaleala District, Afar Region, Northeast Ethiopia. International breastfeeding journal. 2017;12(1):1-10.

35. Delelegn MW, Endalamaw A, Belay GM. Determinants of Acute Diarrhea Among Children Under-Five in Northeast Ethiopia: Unmatched Case-Control Study. Pediatric Health, Medicine and Therapeutics. 
2020;11:323.

Page 21/21 